\title{
Early and Later Adoptions Have Different Long-Term Effects on Male Rat Offspring
}

\author{
Arnaud Barbazanges, Monique Vallée, Willy Mayo, Jamie Day, Hervé Simon, Michel Le Moal, and \\ Stefania Maccari \\ Psychobiologie des Comportements Adaptatifs, Institut National de la Santé et de la Recherche Médicale U. 259, \\ Université de Bordeaux II, 33077 Bordeaux, France
}

\begin{abstract}
Both prenatal and postnatal environmental factors exert complex influences on the development of an organism. Previous studies have demonstrated that intervening events during the prenatal period can have different and even opposite effects than similar intervening events occurring in the postnatal period. We have reported previously that early postnatal adoption prevents prenatal stress-induced long-term impairments in glucocorticoid feedback. To characterize further the effects of adoptions during the postnatal period, adoptions have been performed at different times, and the effect on the postnatal ontogeny of the hypothalamo-pituitary-adrenal axis has been investigated. Adoptions were performed during the first hour after birth (A1) and on the fifth (A5) and twelfth (A12) days after birth. At each of these times, other litters (S1, S5, S12) underwent a "separation" controlling for the 1 min maternal separation necessary for the adoptions. Locomotor behavior, cognition, and stress-induced corticosterone secretion in the adult male offspring have been examined, along with maternal be-
\end{abstract}

Prenatal and postnatal environments exert complex and long-term influences on the development of an organism. For example, animals stressed during pregnancy can bear offspring with reduced male sexual activity, enhanced emotional reactivity (Thompson, 1957; Ward and Weisz, 1984; Weinstock et al., 1988), increased propensity to self-administer drugs (Deminière et al., 1992), and an increased risk of depression-like symptoms in adulthood (Alonso et al., 1991). One of the neurobiological substrates possibly mediating these behavioral consequences of prenatal perturbations is a dysregulation of the hypothalamo-pituitary-adrenal (HPA) axis, a major component of an animal's stress response. In this respect, prenatal stress induces in adult rats an increased (Peters, 1982; Takahashi et al., 1988) and prolonged stressinduced corticosterone secretion (Fride et al., 1986) associated with decreased numbers of hippocampal corticosteroid receptors (Maccari et al., 1995). Such prenatal stress-induced effects may be mediated by increased maternal corticosterone secretion during the prenatal stress procedure (Barbazanges et al., 1996) and/or by postnatal factors such as impaired maternal behavior (Moore and Power, 1986; Power and Moore, 1986). Thus, an early adoption, which increases maternal behavior, prevents prenatal stress-

Received May 7, 1996; revised Aug. 19, 1996; accepted Sept. 18, 1996.

This study was supported by the Institut National de la Santé et de la Recherche Médicale, the Université de Bordeaux II, and the Conseil Régional d'Aquitaine. J.D. is supported by a Human Frontiers Science Program fellowship.

Correspondence should be addressed to Stefania Maccari, INSERM U259, Université de Bordeaux II, Rue Camille Saint Saëns, 33077 Bordeaux Cedex, France. Copyright (C) 1996 Society for Neuroscience $0270-6474 / 96 / 167783-08 \$ 05.00 / 0$ havior. Early adoption (A1) was found to prevent the prolonged stress-induced secretion of corticosterone evident in early separated (S1) offspring. Similarly, A1 rats demonstrated lower novelty-induced locomotion and improved recognition performance in a Y-maze compared to S1 offspring. However, later adoption (A5, A12) prolonged stress-induced corticosterone secretion, increased the locomotor response to novelty, and disrupted cognitive performance in the offspring. Only the early adoption increased maternal licking behavior, a factor that may have a protective effect on the pups. Taken together, these results suggest that the same postnatal manipulation realized at different times can induce different, or even opposite, effects on the behavioral and neuroendocrine characteristics of the adult offspring.

Key words: adoption; stress-induced corticosterone secretion; locomotor activity; recognition memory; spatial learning; maternal behavior; critical period

induced impairments in glucocorticoid feedback (Maccari et al., 1995).

Changes in the postnatal environment, such as modification of the mother-infant interaction, also have specific effects on the development of the animal. Periodic maternal separation for periods of $15 \mathrm{~min}$, known as handling, or maternal deprivation for $4.5 \mathrm{hr}$ during the first 3 weeks of life, is well known to improve the performance of adult and aged offspring in cognitive tasks (Meaney et al., 1988; Escorihuela et al., 1995), to reduce stressinduced corticosterone secretion (Meaney et al., 1988), and to potentiate the negative feedback regulation during restraint stress later in life (Ogawa et al., 1994). Postnatal handling prevents the increased emotional reactivity induced by prenatal stress (Wakshlak and Weinstock, 1990). However, maternal separation is a profound stress applied both to the dams and to the pups, and for this reason it is difficult to determine the biological mechanisms by which such postnatal manipulations exert long-term effects on the offspring. Moreover, this 3 week procedure cannot be used to examine the existence, in the postnatal maturation of neuroendocrine systems, of critical periods that may be characterized by different response sensitivities to stressful stimulation. It is reasonable to consider this last point given that the development of the glucocorticoid receptors implicated in the regulation of the HPA axis shows a distinct postnatal pattern (Sarrieau et al., 1988; Meaney et al., 1993; Rosenfeld et al., 1993) and can be influenced by environmental events (Sarrieau et al., 1988; Meaney et al., 1989). 
To characterize the influence of the postnatal environment on the pup's development, and based on the literature summarized above, the aim of the present experiment was to study whether adoption during different critical periods can have different cognitive and endocrine effects on the adult offspring. Adoptions were carried out either several hours after birth or on the fifth or twelfth day after birth. These periods were chosen because they fall before, during, and at the end of the stress hyporesponsive period (Shapiro, 1962; Sapolsky and Meaney, 1986), which is considered a "critical period" of postnatal maturation of the HPA axis. In addition, whether altered maternal behavior can explain the observed adoption-induced differences in the adult offspring was also examined.

\section{MATERIALS AND METHODS \\ General methods}

\section{Subjects}

Virgin female Sprague Dawley rats weighing 220-250 gm were housed for $6 \mathrm{~d}$ in the presence of a sexually experienced male Sprague Dawley rat weighing $450-500 \mathrm{gm}$. At the end of this period, the pregnant females were individually housed with ad libitum access to food and water. Light/dark cycle (lights on at 8:00 A.M., off at 8:00 P.M.), temperature $\left(22^{\circ} \mathrm{C}\right)$, and humidity $(60 \%)$ were kept constant.

\section{Adoption procedures}

One group of dams and litters served as controls and was left undisturbed. Three groups underwent the postnatal manipulation of adoption at different times: during the first 3-6 hr after birth (day 1), the fifth day (day 5), or the twelfth day (day 12) of lactation. During this procedure, the mothers were removed for $<1 \mathrm{~min}$ from their cages. Then, all pups of the same age and litter were exchanged to the cage of another litter, the mother of which became the adoptive mother. In addition, three "separated" groups were used to control for any possible effects of a single separation of 1 min: at each of the three times, biological mothers were briefly removed from their cages and then returned. Litters containing $<12$ or $>16$ pups, and those not containing approximately equal numbers of males and females, were eliminated from the study given that the culling of litters normally conducted would in fact act as an additional manipulation. Offspring were weaned $21 \mathrm{~d}$ after birth, group-housed, and left undisturbed until testing at $90 \mathrm{~d}$ of age. No more than 2 male siblings per litter were tested in adult life, and each group contained between 8 and 10 rats.

\section{Corticosterone assay}

Corticosterone levels were determined by radioimmunoassay using a highly specific corticosterone antiserum (Kit ICN Biomedicals, Costa Mesa, CA). The minimum level of detection was $0.2 \mu \mathrm{g} / 100 \mathrm{ml}$, and the intra- and interassay coefficients of variation were 5 and $9 \%$, respectively.

\section{Activity measures and cognitive tests}

Locomotor activity. Locomotor activity was measured in a novel environment consisting of a circular corridor $(10 \mathrm{~cm}$ wide, $70 \mathrm{~cm}$ diameter $)$. Four infrared photocells placed at the perpendicular axes of this apparatus automatically recorded locomotion. A single locomotor count was recorded by a microprocessor when neighboring beams were broken. Animals were tested between 4:00 P.M. and 6:00 P.M., and locomotion was recorded in 10 min intervals over a period of $2 \mathrm{hr}$.

Recognition memory. Recognition memory was measured in a Y-maze made of gray plastic. Each arm was $50 \mathrm{~cm}$ long, $16 \mathrm{~cm}$ wide, $32 \mathrm{~cm}$ high, and equipped with two infrared beams $22 \mathrm{~cm}$ apart crossing each arm 3 $\mathrm{cm}$ above the floor. The beams were located 47 and $25 \mathrm{~cm}$ from the end of the arms. A visit to an arm was recorded only when proximal and distal beams were interrupted in succession. Interruption of these infrared beams was recorded on a microcomputer (IBM-PC) outside of the testing room. The floor of the maze was covered with rat odor-saturated sawdust, and after each trial the sawdust was mixed so as to eliminate olfactory cues. The maze was placed in a sound-attenuated room with dim illumination. Numerous visual cues were placed on the walls of the testing room and were kept constant during the behavioral testing sessions. The task consisted of two trials separated by a time interval. In the first trial, one arm of the Y-maze was closed with a guillotine door. Rats were placed in an arm, their head pointing away from the center of the maze, and were allowed to visit the two arms for $10 \mathrm{~min}$. During the intertrial time, rats were housed in their home cages located in a room different than the test room. During the second trial, animals had free access to all three arms and were again allowed to explore the maze for $10 \mathrm{~min}$. Given that the number of visits and the time spent in the novel arm are correlated (Dellu et al., 1994), we only recorded the number of explorations in each arm. The number of visits in the novel arm was calculated as a percentage of the total number of visits in all three arms during the first 2 min of the second trial. This time has been chosen because it has been demonstrated previously that exploratory activity in this novel environment does not last longer than 2 min (Dellu et al., 1992).

Spatial learning. Spatial learning was assessed in a water maze in which animals were required to find a platform submerged $(2 \mathrm{~cm})$ in a $1.8 \mathrm{~m}$ diameter pool of opaque water $\left(21^{\circ} \mathrm{C}\right)$ using only distal, spatial cues available within the testing room. Rats are proficient but reluctant swimmers and readily use the platform to escape the water. The platform was hidden in one of four quadrants, halfway between the sidewalls and the center of the pool. Four trials were performed each day, and each trial began with the animal placed into the pool facing the sidewalls, never at the same location for successive trials. Numerous visual cues were placed on the walls of the testing room and were kept constant during the behavioral testing sessions. Each trial ended when the animals found the platform and remained there for $20 \mathrm{sec}$, or after $90 \mathrm{sec}$ of swimming. The criteria measured were the distance and the latency elapsed to climb onto the platform, and these parameters were analyzed by an automatic videotracking system (Viewpoint, Lyon, France). This test has been used previously to measure spatial learning memory (Morris, 1984; Brandeis et al., 1989).

\section{Maternal behavior}

In a separate group of dams and litters, maternal behavior was monitored after an identical adoption procedure to that described above. Virgin female Sprague Dawley rats weighing 220-250 gm were used. Both foster and biological mothers were removed from their cages for $1 \mathrm{~min}$, and the pups were distributed around the cage. Maternal behavior was observed for $15 \mathrm{~min}$ from the moment the mother was reintroduced into the cage, and the behavioral parameters recorded were the latency of the dam to begin licking a pup and the time spent licking pups during this $15 \mathrm{~min}$. These parameters provide reliable information on maternal behavior and are used widely in studies on laboratory rats (Haney et al., 1989; Mann, 1993). Given that the observations require a manipulation of the dam, an undisturbed control group could not be included in this experiment, which thus included only the adoption and separated groups. Each group contained between 15 and 20 mothers.

\section{Procedures}

\section{Experiment 1a: influence of postnatal manipulation on stress- induced corticosterone secretion}

Male adult offspring of all groups (control, separated, and adopted at each of the three postnatal periods studied) were submitted to a $30 \mathrm{~min}$ restraint stress at $90 \mathrm{~d}$ of age. These rats had been housed individually for $15 \mathrm{~d}$ before this experiment so as to eliminate the variability induced by dominant/submissive relationships established in the group. In fact, submissive rats have been shown to have higher corticosterone levels (Popova and Naumenko, 1972). Restraint was carried out in plastic cylinders (6 cm diameter, $20 \mathrm{~cm}$ long), and corticosterone levels were determined in four blood samples $(250 \mu \mathrm{l})$ withdrawn from the tail vein before stress, 30,120 , and 180 min later.

\section{Experiment 1b: influence of postnatal manipulation on performance of behavioral tests in adult offspring}

After measurement of the stress-induced corticosterone secretion, the same animals were allowed a $7 \mathrm{~d}$ recovery period before behavioral testing. The first behavioral test was the locomotor activity response to novelty in which animals were tested between 4:00 P.M. and 6:00 P.M. Locomotion was recorded in $10 \mathrm{~min}$ intervals over a period of $2 \mathrm{hr}$.

After a second $7 \mathrm{~d}$ recovery period, the second behavioral test, consisting of an arm discrimination in a Y-maze, was conducted. Intertrial intervals of $1 \mathrm{~min}, 4 \mathrm{hr}$, and $6 \mathrm{hr}$ were used. The intertrial interval of $1 \mathrm{~min}$ served as a control for novelty exploration, and rats that did not reach a criterion of $40 \%$ visits to the novel arm (a random exploration being $33 \%$ ) were not considered for the following analyses, in which the longer delays served as memory tests. This criterion of $40 \%$ is usually used to 


\section{Exposure to restraint stress}

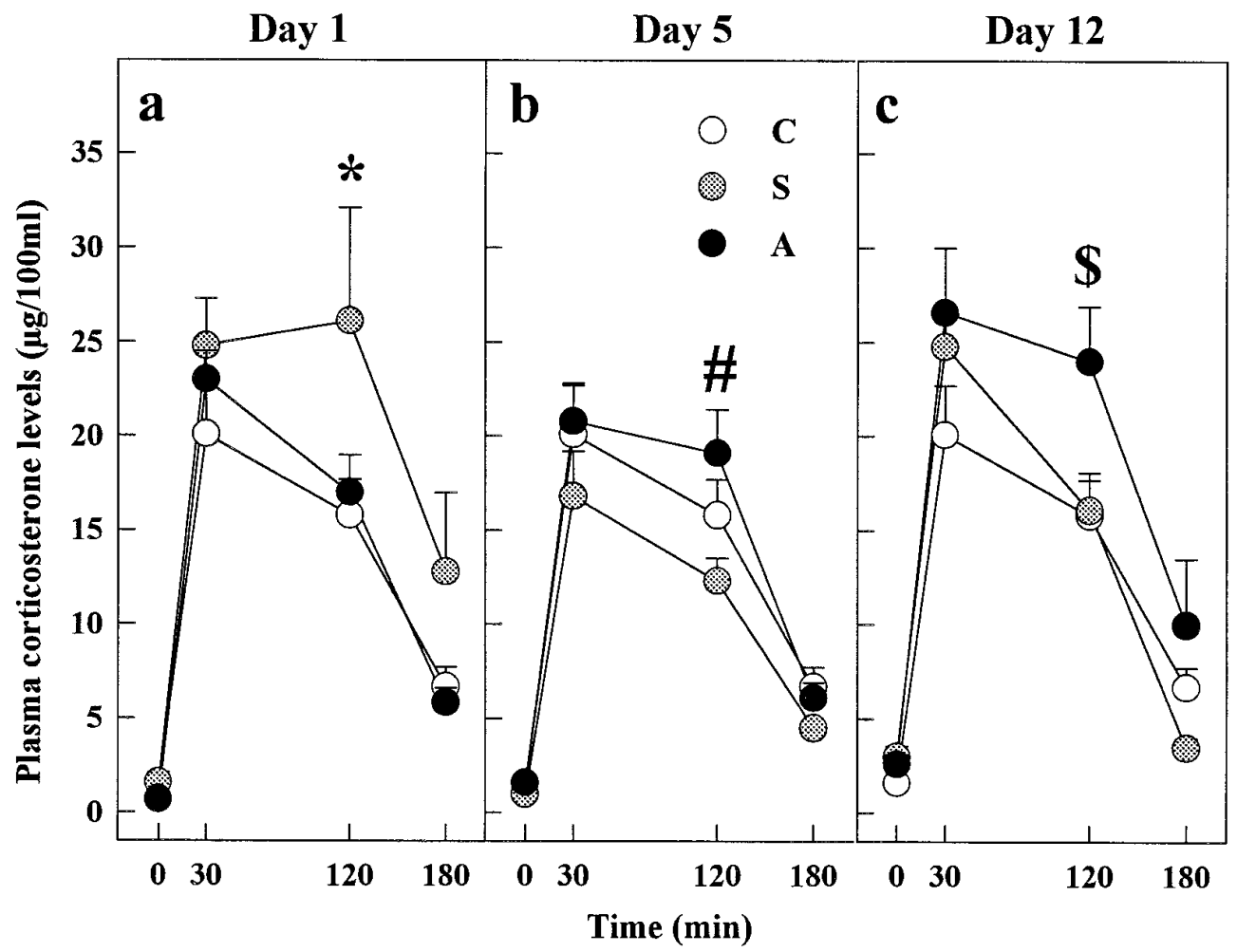

Figure 1. Plasma corticosterone secretion after restraint stress in adult offspring. $a$, Rats separated at day 1 (S1) differ from controls (C) and from the adopted group (A1) with respect to corticosterone levels 120 min after stress. $b$, Rats adopted at day 5 (A5) show higher corticosterone levels $120 \mathrm{~min}$ after stress than does the separated group (S5). $c$, Rats adopted at day 12 (A12) differ from the other two groups at the time point 2 hr after the stress. ${ }^{*} p<0.05 \mathrm{~S} 1$ versus both $\mathrm{C}$ and $\mathrm{A} 1 ;{ }^{\#} p<0.05$ A5 versus S5; $\$_{p}<0.05 \mathrm{~A} 12$ versus both $\mathrm{C}$ and $\mathrm{S} 12$. Error bars represent SEM.

assess that rats do not have any problem of novelty exploration (Dellu et al., 1994). The different intertrial intervals were tested in ascending order, separated by pauses of $7 \mathrm{~d}$ each and in a different room for each of the intertrial tests.

One week after finishing the Y-maze experiments, the third behavioral experiment measuring spatial learning in a Morris water maze was conducted. All animals were given 36 trials over 9 d, between 12:00 P.M. and 6:00 P.M., with the platform submerged. The latency and the distance covered to find the platform were recorded. On the 10th day, four trials were carried out with the platform elevated $(2 \mathrm{~cm})$ above the surface of the water in a different location. Animals that could not use the obvious visual cue of the platform to rapidly escape the water were not considered for analyses of the previous 36 trials or for the Y-Maze analysis.

\section{Experiment 2: influence of postnatal treatment on}

\section{maternal behavior}

In a separate group of dams and litters, the maternal behavior of foster and biological mothers was evaluated for each adoption time, between 5:00 P.M. and 7:00 P.M.

\section{Statistics}

For the behavioral tests of experiment 1, other than the Y-maze, the results were compared by two-way ANOVA for the three groups (adopted, separated, and controls) at each day of adoption, and the NewmanKeuls test was used as a post hoc test. To analyze the Y-maze results, we initially performed a two-way ANOVA to verify that the two non-novel arms were explored equally. Then, so as to accomplish a qualitative analysis between the groups, a Student's $t$ test was used to assess departures from chance levels (33\%) of performance in each group (Dellu et al., 1994). In experiment 2 , the influence of adoption on maternal behavior was analyzed by two-way ANOVA comparing separated and adoptive mothers.

\section{RESULTS}

\section{Experiment 1a: effects of adoption on stress-induced corticosterone secretion in adult offspring (Fig. 1)}

Manipulation at day 1 modifies corticosterone secretion (group effect $\left.F_{(2,26)}=3.984, p=0.03\right)$, the separated group (S1) showing a higher secretion of corticosterone than the other two groups (post hoc, $p=0.02$ in comparison with both the control and adopted groups). Although neither basal corticosterone levels nor those 30 or 180 min after stress differed among the three groups, corticosterone secretion $2 \mathrm{hr}$ after stress was higher in the separated rats than in the control rats (group effect $F_{(2,26)}=3.807, p=$ 0.03 ; post hoc $p=0.02$ and $p=0.04$ with respect to control and adopted groups, respectively).

Postnatal treatment at day 5 also modified corticosterone secretion (group effect $F_{(2,27)}=3.471, p=0.04$ ), but in this case the difference was found between the adopted group (A5) and the separated group (S5), the former showing higher levels of stressinduced corticosterone secretion than the latter (post hoc, $p=$ $0.04)$. This group difference was found at the time point $2 \mathrm{hr}$ after the stress (group effect $F_{(2,27)}=3.352, p=0.05$, post hoc, A5 versus $\mathrm{S} 5, p=0.03$ ), whereas there were no differences in basal corticosterone levels, or those 30 or 180 min after stress.

Stress-induced corticosterone secretion was also modified by adoption at day 12 (group effect $F_{(2,26)}=3.652, p=0.04$ ), adopted rats (A12) showing higher secretion than control (C) ( post hoc, $p=0.04$ ) and separated (post hoc, $p=0.04$ ) rats (S12). This effect was again attributable only to a difference $2 \mathrm{hr}$ after stress, at which time corticosterone secretion was higher in the adopted rats (A12) than in either the separated (S12) or control (C) rats (post hoc, $p=0.05$ for both comparisons).

\section{Experiment 1b: effects of adoption on behavior in adult offspring}

\section{Locomotor activity (Fig. 2)}

The total locomotor activity over $2 \mathrm{hr}$ differed between the controls and the groups adopted or separated at day 1 (group effect $F_{(2,26)}=3.233, p=0.05$ ) in a time-independent manner (group $\times$ time interaction, not significant). Post hoc analysis indicated that 


\section{Locomotor activity}



Figure 2. Novelty-induced locomotor activity in adult offspring. $a$, Total locomotor activity over $2 \mathrm{hr}$ is higher in the separated group (S1) in comparison with the control group (C). $b$, Rats adopted at day 5 (A5) show a higher total locomotor activity over $2 \mathrm{hr}$ than do the control rats and those separated at day 5 (S5). $c$, Rats adopted at day 12 (A12) show higher total locomotor activity over $2 \mathrm{hr}$ than the separated (S12) rats. ${ }^{*} p<0.05 \mathrm{~S} 1$ versus $\mathrm{C}$; ${ }^{\#} p<0.05$ A5 versus both $\mathrm{C}$ and S5; $\$ p<0.05$ A12 versus S12. Error bars represent SEM.

this effect was attributable to a higher locomotor response to novelty in the separated group (S1) with respect to the control group ( post hoc, $p=0.03$ ). Furthermore, adopted rats (A1) did not differ from control rats (post hoc, not significant). It is interesting to note that the locomotor response to novelty pattern was similar to the corticosterone levels in response to restriction.

Postnatal treatment at day 5 also modified novelty-induced total locomotor activity (group effect $F_{(2,25)}=3.169, p=0.02$ ), but in this case the adopted (A5) rats showed a higher locomotor activity than did the other two groups (post hoc, $p=0.04$, A5 vs $\mathrm{C}$ and S5). In addition, the group $\times$ time interaction was not significant.

Total locomotor activity over $2 \mathrm{hr}$ in response to novelty also differed between the groups adopted or separated at day 12 and the controls (group effect $F_{(2,26)}=5.194, p=0.01$ ), but in this case the A12 group showed a higher locomotor response only in comparison to the $\mathrm{S} 12$ group ( post hoc, $p=0.01$ ). There was no group $\times$ time interaction.

\section{Recognition memory in a Y-maze (Fig. 3) Intertrial interval: $1 \mathrm{~min}$}

Independently of the novel arm, the other two arms were explored at a similar frequency (arm effect $\left.F_{(1,122)}=1.320, p=0.25\right)$. For each rat tested, in each group, the percentage of visits to the novel arm was significantly above chance level. Thus, no rat failed to reach the criterion of novelty exploration.

\section{Intertrial interval: $\mathbf{4} \mathbf{~ h r}$}

First, independently of the novel arm, the other two arms were explored at a similar frequency (arm effect $F_{(1,122)}=2.592, p=$ 0.11 ). Second, all groups continued to recognize novelty at the 4 hr delay. The percentage of visits to the novel arm was above chance level in the adopted offspring (A1: $43 \pm 3 \%, t=3.33$, df $=$ $9, p<0.01$; A5: $45 \pm 4 \%, t=3$, df $=7, p<0.02$; A12: $41 \pm 3 \%$, $t=2.66$, df $=7, p<0.05$ ), in the separated offspring (S1: $45 \pm$ $4 \%, t=3, \mathrm{df}=7, p<0.02 ; \mathrm{S} 5: 45 \pm 4 \%, t=3$, df $=7, p<0.02$;
S12: $48 \pm 4 \%, t=3.75$, df $=7, p<0.01$ ), and in the controls $(44 \pm 3 \%, t=3.66, \mathrm{df}=9, p<0.01)$.

\section{Intertrial interval: $\mathbf{6 ~ h r}$}

Independently of the novel arm, the other two arms were explored at a similar frequency ( $\operatorname{arm}$ effect $F_{(1,122)}=0.08, p=0.767$ ).

Discrimination of the novel arm at the $6 \mathrm{hr}$ delay differed among the adopted, separated, and control groups. The control group continued to recognize the novel arm $(45 \pm 4 \%, t=3$, $\mathrm{df}=9, p<0.02$ ), as did the group adopted at day 1 (A1: $44 \pm$ $2 \%, t=5.5$, df $=9, p<0.001)$, whereas their separated counterparts (S1) responded at the level of chance (38 $\pm 3 \%$, $t=1.66, \mathrm{df}=7, p>0.1$ ).

Both groups treated on postnatal day 5 recognized novelty at the $6 \mathrm{hr}$ intertrial delay (A5: $41 \pm 3 \%, t=2.66$, df $=7, p<0.05$; S5: $48 \pm 5 \%, t=3$, df $=7, p<0.02)$.

Whereas the percentage of visits to the novel arm was still above chance level for the offspring of the group separated at day 12 (S12: $45 \pm 3 \%, t=4$, df $=7, p<0.01)$, this was not the case for adopted offspring (A12: $40 \pm 4 \%, t=2$, df $=7, p>0.05$ ).

\section{Spatial learning in Morris water maze (Fig. 4)}

Distances to find the hidden platform (an average of the 4 trials per day) are presented in Figure 4. Statistical analysis of distance and latency data revealed that the experimental groups C, A1, and $\mathrm{S} 1$ performed similarly in this test.

However, a significant group effect $\left(F_{(2,23)}=3.895, p<0.05\right)$ was observed for the groups $\mathrm{C}, \mathrm{A} 5$, and $\mathrm{S} 5$ on the distance covered to find the platform. Post hoc analysis indicated that the adopted offspring (A5) covered more territory than controls (C) to find the platform ( post hoc, $p=0.02$ ). Similar results were found for the latency data: a significant group effect $\left(F_{(2,23)}=4.023, p<0.05\right)$ and a significant group $\times$ time interaction $\left(F_{(16,184)}=1.891, p=\right.$ 0.02) were observed for the groups C, A5, and S5. Post hoc 


\section{Arm discrimination in a Y-maze}

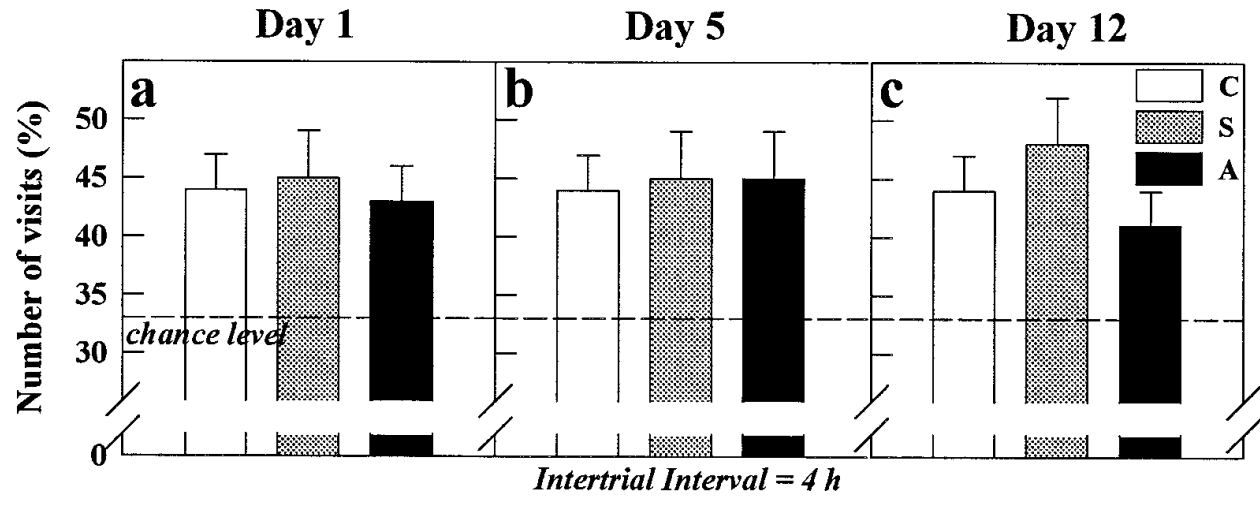

Figure 3. Arm discrimination in a Y-maze in adult offspring at 4 and $6 \mathrm{hr}$ delays. $a$, For the $4 \mathrm{hr}$ delay, the percentage of visits to the novel arm is above chance level in the adopted, separated, and control groups at day 1 . For the $6 \mathrm{hr}$ delay, the percentage of visits to the novel arm is above chance level in both the control group (C) and the group adopted at day 1 (A1), whereas the separated group (S1) responds at the level of


chance. $b$, For the $4 \mathrm{hr}$ delay, the percentage of visits to the novel arm is above chance level in the control group (C) and those adopted (A5) and separated (S5) at day 5. For the $6 \mathrm{hr}$ delay C, A5, and S5 rats visited the novel arm at above chance levels. $c$, For the $4 \mathrm{hr}$ delay, the percentage of visits to the novel arm is above chance level in the control group (C) and those adopted (A12) or separated (S12) at day 12. For the $6 \mathrm{hr}$ delay, the percentage of visits to the novel arm is above chance level in C and S12, but not in the A12 rats. *, Response at the level of chance. Error bars represent SEM.

analysis indicated that the adopted offspring (A5) took longer than controls $(\mathrm{C})$ to find the platform ( post hoc, $p=0.02$ ).

Postnatal treatment at day 12 also affected spatial learning as indicated by the fact that the distances covered to find the plat- form were significantly different among the groups $\mathrm{C}, \mathrm{A} 12$, and $\mathrm{S} 12\left(F_{(2,23)}=4.679, p=0.01\right)$, the adopted rats (A12) swimming farther than both the controls (C) (post hoc, $p=0.03$ ), and the separated offspring (S12) ( post hoc, $p=0.03$ ). The rats adopted

\section{Spatial learning in the water maze}

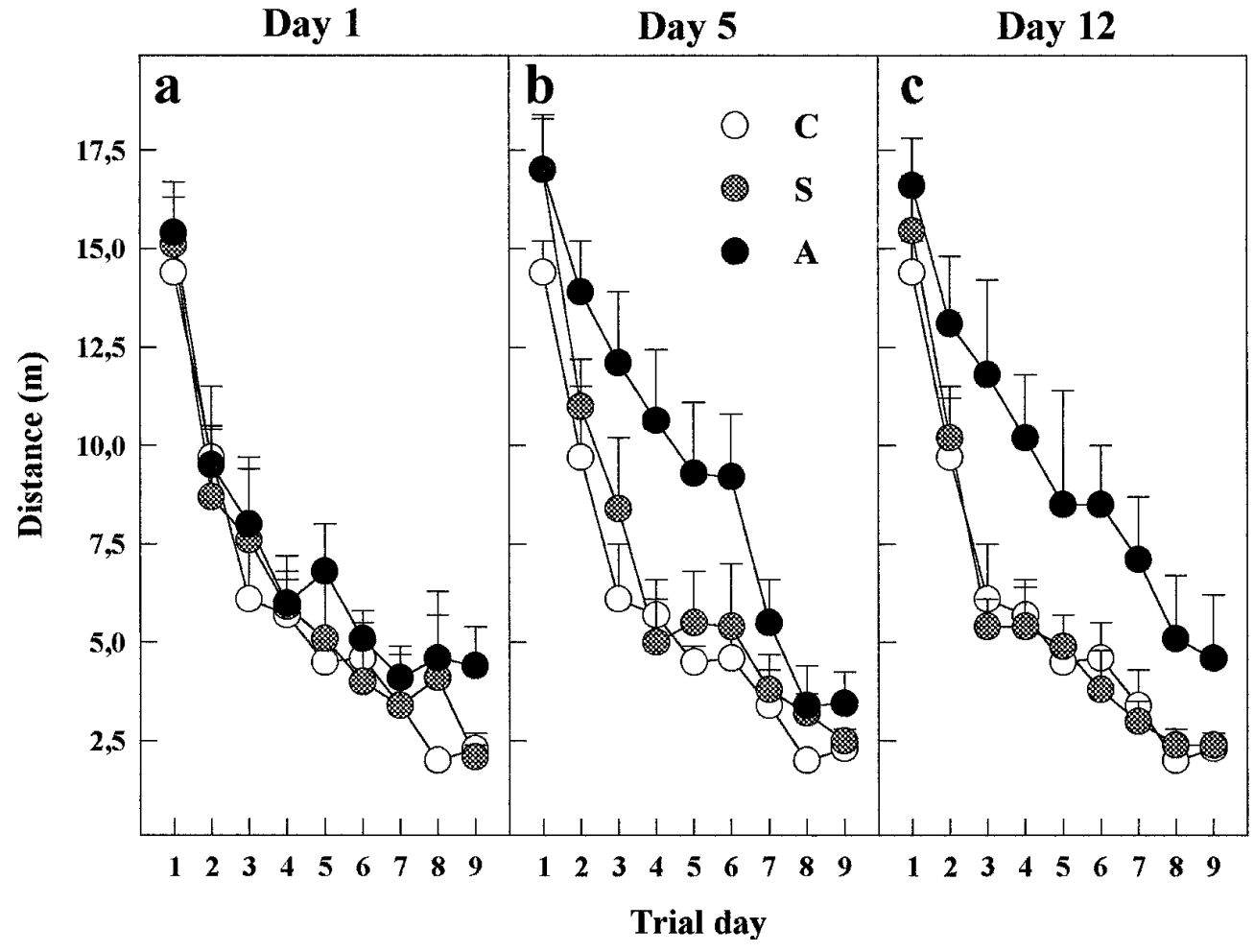

Figure 4. Spatial learning in the Morris water maze in adult offspring. $a$, The groups adopted (A1) or separated (S1) on day 1 perform similarly to the controls (C) in this test. $b$, The group adopted on day 5 (A5) covered more territory than controls $(\mathrm{C})$ to find the platform. $c$, The group adopted at day 12 (A12) shows longer distances to find the platform than both the controls (C) and the separated offspring (S12). 
at day 12 also showed longer latencies $\left(F_{(2,23)}=4.066, p<0.05\right)$ than both the controls $(\mathrm{C})$ ( post hoc, $p=0.04$ ) and the separated offspring (S12) (post hoc, $p=0.04$ ) to find the platform.

\section{Experiment 2: influence of postnatal treatment on maternal behavior (Fig. 5)}

The adoption procedure, when performed in the first 3-6 hr of the pups' lives, increased maternal behavior. The latency to start licking the pups (licking latency) was lower in the adoptive dams than in the biological mothers that had undergone the separation procedure $\left(F_{(1,48)}=6.346, p=0.01\right)$. In addition, adoptive mothers spent more total time licking the pups than did the biological mothers $\left(F_{(1,48)}=9.404, p<0.01\right)$.

Adoptions carried out on day 5 , on the other hand, did not affect the licking latency $\left(F_{(1,28)}=0.224, p=0.6\right)$. Although adoptive mothers (A5) spent slightly more time licking pups than did the biological mothers (S5), this effect was not statistically significant $\left(F_{(1,28)}=3.519, p=0.07\right)$, and it seems, therefore, that the day 5 treatment did not significantly affect maternal behavior.

Similarly, adoption at day 12 had no effect on maternal behavior. The latency and total time licking the pups were not different between the two groups of mothers (latency: $F_{(1,19)}=0.098, p=$ 0.7 ; time: $\left.F_{(1,19)}=0.014, p=0.9\right)$.

\section{DISCUSSION}

These experiments provide evidence that postnatal adoptions and separations have different behavioral and endocrine effects on the adult offspring, depending on the time of the postnatal treatment. Adult rats that have undergone a 1 min separation within the first 3-6 hr of life display an increased locomotor reactivity to novelty and decreased recognition capacities in a Y-maze test, but no changes of spatial learning in a water maze. The early separation also prolongs stress-induced corticosterone secretion. The adoption procedure carried out on day 1 prevents all of these long-term effects induced by the early separation. In contrast, adult offspring of day 5 and 12 adoptions exhibit increased locomotor reactivity to novelty and impaired spatial learning in the water maze, and rats adopted at day 12 demonstrate impaired recognition memory at the $6 \mathrm{hr}$ delay. Moreover, both later adoptions have long-term endocrine effects in that stress-induced corticosterone secretion is prolonged in the adult offspring. Taken together, as summarized in Table 1, these results suggest that the later adoptions (A5 or A12) have long-term effects that are (1) similar to those of the earlier separation (S1) procedure, (2) different than those of the earlier adoption (A1), and (3) generally an impairment both of the psychobiological response to stress and memory capacity of the adult offspring.

Our results show that damaging early life events can be prevented by another intervention. In fact, the adoption procedure carried out on day 1 prevented all of the above long-term effects induced by the early separation. This result is similar to previous data showing that an early adoption prevents the prolonged stressinduced corticosterone secretion (Maccari et al., 1995) and that postnatal handling prevents the decreased exploratory behavior (Wakshlak and Weinstock, 1990) of prenatally stressed rats.

In the $\mathrm{A} 5$ and $\mathrm{A} 12$ rats, the prolonged corticosterone secretion in response to novelty was associated with increased locomotor reactivity and impairment of cognitive functioning. This result suggests that a dysfunctioning of HPA axis activity represents one of the biological mechanisms correlated with behavioral impairments. Indeed, previous reports have shown that impairments in glucocorticoid secretion are associated with behavioral disorders in adults (Persky, 1975; Pepper and Krieger, 1984; Sapolsky et al., 1986; Holsboer, 1989; Piazza et al., 1991). In comparison with the effects of postnatal treatments, consisting of periodic maternal separation during the first 3 weeks of life (Meaney et al., 1988; Ogawa et al., 1994; Escorihuela et al., 1995) or those of the early adoption shown in this paper, the later adoptions have different, or even opposite, long-term effects in the offspring. In fact, the behavioral and endocrine responses of the offspring appear to deviate farther from normal with increasing delay between birth and adoption. Together, these results suggest the existence of postnatal critical periods during which environmental stimulation can cause disadaptive development.

To explain how these different long-term effects are caused by manipulation within specific periods of development, one might first consider that modifications of the mother-pup interaction are associated with a complex short-term physiological response in the pup. For example, separation from the dam of neonatal rat pups ( $1 \mathrm{hr})$ is associated with a decline in the activity of ornithine decarboxylase, a sensitive index of growth and differentiation (Butler et al., 1978; Evoniuk et al., 1979; Schanberg and Kuhn, 1985), and with an increase in corticosterone secretion (Pauk et al., 1986; Stanton et al., 1988; Kuhn et al., 1990) in the pups. Notably, these responses were found to be dependent on which day after birth the maternal separation was conducted (Kuhn et al., 1990; D'Amato et al., 1992) and, at least in part, on specific maternal behaviors. Indeed, absence of active tactile stimulation, such as anogenital licking of the pups by the dams, has been demonstrated previously to decrease ornithine decarboxylase activity in neonatal rat pups (Butler et al., 1978; Pauk et al., 1986), an effect that involves downregulation of the proto-oncogenes c-myc and max in the pups (Wang et al., 1996). Furthermore, it has been demonstrated that activity of the HPA axis in infant rats, previously suggested to be dependent on contact with the dam (Stanton and Levine, 1990), can be regulated by experimental manipulation mimicking maternal anogenital stroking of the pups (Suchecki et al., 1993). Anogenital licking of the pups has also been associated with maturation of sexual behavior in male offspring (Moore, 1984, 1992), as has infantile experience with suckling odors (Fillion and Blass, 1986).

One of the most obvious potential substrates for the postnatally induced alterations in adulthood is maternal behavior, as discussed above; this idea, therefore, was examined in the second experiment. Adoptions at day 1 stimulated maternal behavior, in that the dams demonstrated decreased latency and increased total time in licking the pups. This observation is in agreement with another study, which showed that dams retrieved foster pups more quickly than their natural offspring (Misanin et al., 1977) and may explain, at least in part, the protective effect of the early adoption on the behavioral and neuroendocrine changes caused by the early separation. Together, these results suggest that the early separation, when not counteracted by the adoption-induced increased maternal behavior, may act as a stressor and affect the maturation of the pup's endocrine system, and thus perhaps also explain the behavioral detriments noted in these adults. In opposition to this pattern noted in rats that had undergone treatment at day 1 , however, rats that were adopted at days 5 and 12 showed disturbed behavioral and endocrine measures in adulthood. Thus, the disturbances noted in the adult offspring of later adoptions may be caused by changes to the endocrine system resulting from adoption-induced stress that was not counteracted by augmented maternal behavior.

The fact that maternal licking behavior was increased in adop- 


\section{Maternal Behavior}

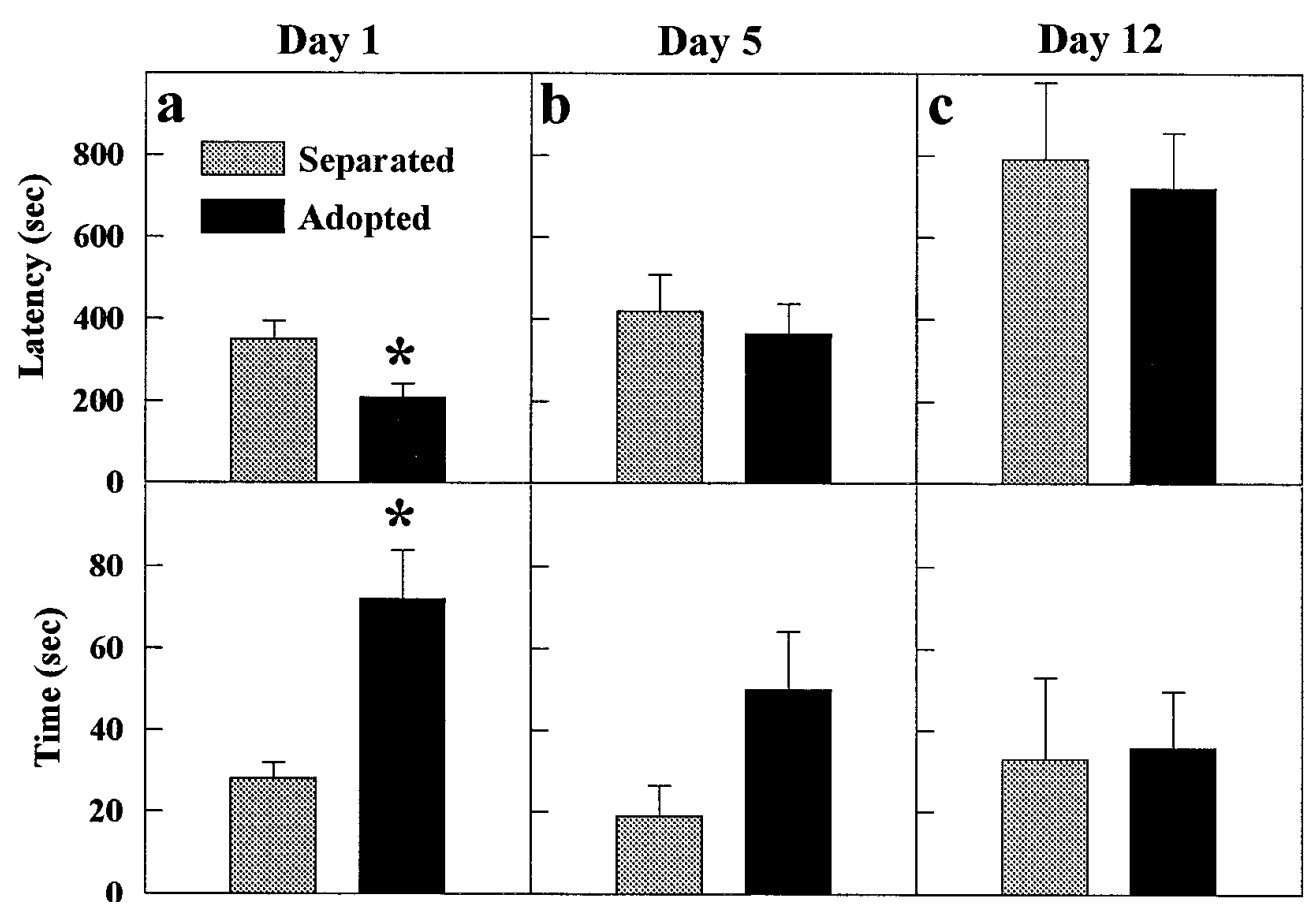

Figure 5. Maternal behavior in separated and adoptive dams. $a$, The latency to start licking the pups (licking latency) is lower, and the total time spent licking the pups is higher, in the dams undergoing the adoption procedure at day 1 than in the biological mothers undergoing the separation procedure. Adoptions carried out on day $5(b)$ and day 12 (c) did not affect the licking latency or the total time spent licking the pups. ${ }^{*} p<0.05 \mathrm{~A} 1$ versus S1. Error bars represent SEM. tive dams only after the day 1 adoption must be considered. It is well known that maternal behavior is stimulated by olfactory and auditory stimuli from the pups. Indeed, many studies have established that maternal olfaction is involved in stimulating maternal licking (Moore and Samonte, 1986; Brouette-Lahlou et al., 1991), and ultrasonic calls from the pups may induce anogenital licking of the pups by the dam (Brouette-Lahlou et al., 1992). The fact that these behaviors are augmented in the foster dams at day 1 ,

\section{Table 1. Summary of results}

Adult offspring responses

\begin{tabular}{|c|c|c|c|c|c|c|c|c|c|}
\hline 1 & $\mathrm{C}$ & S1 & A1 & $\mathrm{C}$ & S5 & A5 & $\mathrm{C}$ & $\mathrm{S} 12$ & A12 \\
\hline 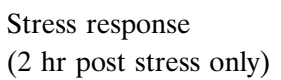 & & $\uparrow_{\mathrm{C}, \mathrm{A}}$ & - & - & - & $\uparrow \mathrm{s}$ & - & - & \\
\hline $\mathrm{OC}$ & - & $\uparrow_{\mathrm{C}}$ & - & - & - & $\uparrow_{\mathrm{C}}$ & - & - & $\uparrow$ \\
\hline $\mathrm{Y}$ & - & I & - & - & - & - & - & - & 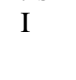 \\
\hline Water Maze & - & - & - & - & - & $\mathrm{I}_{\mathrm{C}}$ & - & - & \\
\hline
\end{tabular}

\begin{tabular}{lccccccc}
\hline \multicolumn{7}{c}{ Maternal behavior } \\
Experiment 2 & S1 & A1 & S5 & A5 & S12 & A12 \\
\hline Latency to licking & - & $\downarrow$ & - & - & - & - \\
Time spent licking & - & $\uparrow$ & - & $\uparrow_{(p=0.07)}$ & - & -
\end{tabular}

Adult rats that have undergone a 1 min separation (S1) within the first 3-6 hr of life display a prolonged stress-induced corticosterone secretion at $2 \mathrm{hr}$ after stress. The early separation (S1) also increases locomotor reactivity to novelty and impairs recognition capacities in a Y-maze test at the $6 \mathrm{hr}$ delay, but does not change spatial learning in a water maze. The adoption procedure carried out on day 1 (A1) prevents all of these long-term effects induced by the early separation. In contrast, adult offspring of day 5 (A5) and 12 (A12) adoptions exhibit prolonged stress-induced corticosterone secretion at $2 \mathrm{hr}$ after stress, increased locomotor reactivity to novelty, and impaired spatial learning in the water maze; rats adopted at day 12 also demonstrate impaired recognition memory at the $6 \mathrm{hr}$ delay. Only adoption at day 1 stimulated maternal behavior. The arrows indicate in which direction the endocrine or behavioral response changed, and the subscripts denote those groups for which the difference was statistically significant. I indicates impaired performance. but not at the later dates, may be attributable to a potential behavioral-hyperresponsive period in the dams' responses to stimuli from their new pups. Indeed, the nonadoptive dams in this experiment demonstrate increased latency to start licking their pups between days 1 and 12. Furthermore, it is interesting to note that handled pups also produce more ultrasonic vocalization (Bell et al., 1971), inducing more maternal care, and possibly the behavioral and biological improvement observed in adult and aged handled rats (Meaney et al., 1988).

In conclusion, changes in the early postnatal environment can have a long-lasting influence. As demonstrated here, the same postnatal treatments carried out on different days can cause diametrically opposed changes in the adult offspring's behavior and HPA axis, and at least some of these postnatally induced changes may be mediated by modifications of maternal behavior. Thus, the postnatal development of rat pups includes critical periods within which the same stimuli can induce different, even opposite, long-term behavioral and endocrine effects.

\section{REFERENCES}

Alonso SJ, Arevalo R, Afonso D, Rodriguez (1991) Effects of maternal stress during pregnancy on forced swimming test behavior of the offspring. Physiol Behav 50:511-517.

Barbazanges A, Piazza PV, Le Moal M, Maccari S (1996) Maternal glucocorticoid secretion mediates long-term effects of prenatal stress. J Neurosci 16:3963-3969.

Bell RW, Nitschke W, Gorry TH, Zachman TA (1971) Infantile stimulation and ultrasonic signaling: a possible mediator of early handling phenomena. Dev Psychobiol 4:181-191.

Brandeis R, Brandys Y, Yehuda S (1989) The use of the Morris water maze in the study of memory and learning. Int J Neurosci 48:29-69.

Brouette-Lahlou I, Vernet-Maury E, Chanel J (1991) Is rat dam licking behavior regulated by pups' preputial gland secretion? Anim Learn Behav 19:177-184.

Brouette-Lahlou I, Vernet-Maury E, Vigouroux M (1992) Role of pups' ultrasonic calls in a particular maternal behavior in Wistar rat: pups anogenital licking. Behav Brain Res 50:147-154. 
Butler SR, Suskind MR, Schanberg SM (1978) Maternal behavior as a regulator of polyamine biosynthesis in brain and heart of the developing rat pup. Science 199:445-447.

D'Amato FR, Cabib S, Puglisi-Allegra S, Patacchioli FR, Cigliana G, Maccari S, Angelucci L (1992) Effects of acute and repeated exposure to stress on the hypothalamo-pituitary-adrenocortical activity in mice during postnatal development. Horm Behav 26:474-485.

Dellu F, Mayo W, Cherkaoui J, Le Moal M, Simon H (1992) A two-trial memory task with automated recording: study in young and aged rats. Brain Res 588:132-139.

Dellu F, Mayo W, Vallee M, Le Moal M, Simon H (1994) Reactivity to novelty during youth as a predictive factor of cognitive impairment in the elderly: a longitudinal study in rats. Brain Res 653:51-56.

Deminière JM, Piazza PV, Guegan G, Abrous N, Maccari S, Le Moal M, Simon H (1992) Increased locomotor response to novelty and propensity to intravenous amphetamine self-administration in adult offspring of stressed mothers. Brain Res 586:135-139.

Escorihuela RM, Tobena A, Fernandez-Teruel A (1995) Environmental enrichment and postnatal handling prevent spatial learning deficits in aged hypoemotional (Roman high-avoidance) and hyperemotional (Roman low-avoidance) rats. Learn Behav 2:40-48.

Evoniuk GE, Kuhn CM, Schanberg SM (1979) The effect of tactile stimulation on serum growth hormone and tissue ornithine decarboxylase activity during maternal deprivation in rat pups. Commun Psychopharmacol 3:363-370.

Fillion TJ, Blass EM (1986) Infantile experience with suckling odors determines adult sexual behavior in male rats. Science 231:729-731.

Fride E, Dan Y, Feldon J, Halevy G, Weinstock M (1986) Effects of prenatal stress on vulnerability to stress in prepubertal and adult rats. Physiol Behav 37:681-687.

Haney M, DeBold J, Miczek K (1989) Maternal aggression in mice and rats towards male and female conspecifics. Aggressive Behav $15: 443-453$.

Holsboer F (1989) Psychiatric implications of altered limbichypothalamic-pituitary-adrenocortical activity. Eur Arch Psychiatry Neurol Sci 238:302-322.

Kuhn CM, Pauk J, Schanberg SM (1990) Endocrine responses to mother-infant separation in developing rats. Dev Psychobiol 23:395-410.

Mann PE (1993) Measurement of maternal behavior. Methods Neurosci 14:343-358.

Maccari S, Piazza PV, Kabbaj M, Barbazanges A, Simon H, Le Moal M (1995) Adoption reverses the long-term impairment in glucocorticoid feedback induced by prenatal stress. J Neurosci 15:110-116.

Meaney MJ, Aitken DH, Van Berkel C, Bhatnagar S, Sapolsky M (1988) Effect of neonatal handling on age-related impairments associated with the hippocampus. Science 239:766-768.

Meaney MJ, Aitken DH, Sharma S, Viau V, Sarrieau A (1989) Postnatal handling increases hippocampal type II, glucocorticoid receptors and enhances adrenocortical negative-feedback efficacy in the rat. Neuroendocrinology 50:597-604.

Meaney MJ, O’Donnell D, Viau V, Bhatnagar S, Sarrieau A, Rose G, Poirier J, Seckl JR (1993) Corticosteroid receptors in the rat brain and pituitary during development and hypothalamic-pituitary-adrenal function. In: Receptors and the developing nervous system (McLaughin P, Zagon I, eds), pp 163-201. London: Chapman and Hall.

Misanin JR, Zawacki DM, Krieger WG (1977) Differential maternal behavior of the rat dam toward natural and foster pups: implication for nutrition research. Bull Psychonom Soc 10:313-316.

Moore CL (1984) Maternal contributions to the development of masculine sexual behavior in laboratory rats. Dev Psychobiol 17:347-356.

Moore CL (1992) Maternal stimulation affects the number of motor neurons in a sexually dimorphic nucleus of the lumbar spinal cord. Brain Res 572:52-56.

Moore CL, Power KL (1986) Prenatal stress affects mother-infant interaction in Norway rats. Dev Psychobiol 19:235-245.

Moore CL, Samonte BR (1986) Preputial glands of infant rats (Rattus norvegicus) provide chemosignals for maternal discrimination of sex. J Comp Psychol 100:76-80.
Morris R (1984) Developments of a water-maze for studying spatial learning memory. J Neurosci Methods 11:47-60.

Ogawa T, Mikuni M, Kuroda Y, Muneoka K, John Mori K, Takahashi K (1994) Periodic maternal deprivation alters stress responses in adult offspring, potentiates the negative feedback regulation of restraint stress-induced adrenocortical response and reduces the frequencies of open field-induced behaviors. Pharmacol Biochem Behav 49:961-967.

Pauk J, Kuhn CM, Field TM, Schanberg SM (1986) Positive effects of tactile versus kinesthetic or vestibular stimulation on neuroendocrine and ODC activity in maternally-deprived rat pups. Life Sci 39:2081-2087.

Pepper GM, Krieger DT (1984) Neurobiology of mood disorders (Post RM, Ballenger JC, eds), pp 245-254. Baltimore: Williams \& Wilkins.

Persky H (1975) Adrenocortical function and anxiety. Psychoneuroendocrinology 1:37-44.

Peters DAV (1982) Prenatal stress: effects on brain biogenic amine and plasma corticosterone levels. Pharmacol Biochem Behav 17:721-725.

Piazza PV, Maccari S, Deminière JM, Le Moal M, Mormède P, Simon H (1991) Corticosterone levels determine individual vulnerability to amphetamine self-administration. Proc Natl Acad Sci USA 88:2088-2092.

Popova N, Naumenko E (1972) Dominance relation and the pituitary adrenal system in the rat. Anim Behav 20:108-114.

Power KL, Moore CL (1986) Prenatal stress eliminates differential maternal attention to male offspring in Norway rats. Physiol Behav 38:667-671.

Rosenfeld P, Van Eekelen JAM, Levine S, De Kloet ER (1993) Ontogeny of corticosteroid receptors in the brain. Cell Neurobiol 13:295-319.

Sapolsky RM, Meaney MJ (1986) Maturation of the adrenocortical stress response: neuroendocrine control mechanisms and the stress hyporesponsive period. Brain Res Rev 11:65-76.

Sapolsky RM, Krey LC, McEwen BS (1986) The neuroendocrinology of stress and aging: the glucocorticoids cascade hypothesis. Endocrinol Rev 7:284-301.

Sarrieau A, Sharma S, Meaney MJ (1988) Postnatal development and environmental regulation of hippocampal glucocorticoid and mineralocorticoid receptors in the rat. Dev Brain Res 43:158-162.

Schanberg SM, Kuhn CM (1985) The biochemical effects of tactile deprivation in neonatal rats. Perspect Behav Med 2:133-148.

Shapiro S (1962) Pituitary ACTH and compensatory adrenal hypertrophy in stress-non-responsive infant rats. Endocrinology 71:986-989.

Stanton ME, Levine S (1990) Inhibition of infant glucocorticoid stress response: specific role of maternal cues. Dev Psychobiol 23:411-426.

Stanton ME, Guitierrez YR, Levine S (1988) Maternal deprivation potentiates pituitary-adrenal stress responses in infant rats. Behav Neurosci 102:692-700.

Suchecki D, Rosenfeld P, Levine S (1993) Maternal regulation of the hypothalamic-pituitary-adrenal axis in the infant rat: the roles of feeding and stroking. Dev Brain Res 75:185-192.

Takahashi LK, Kalin NH, Barksdale CM, Van Der Burgt JA (1988) Stressor controllability during pregnancy influences pituitary-adrenal hormone concentrations and analgesic responsiveness in offspring. Physiol Behav 42:323-329.

Thompson WR (1957) Influence of prenatal maternal anxiety on emotionality in young rats. Science 125:698-699.

Wakshlak A, Weinstock M (1990) Neonatal handling reverses behavioral abnormalities induced in rats by prenatal stress. Physiol Behav 48:289-292.

Wang S, Bartolome JV, Schanberg SM (1996) Neonatal deprivation of maternal touch may suppress ornithine decarboxylase via downregulation of the proto-oncogenes c-myc and max. J Neurosci 16:836-842.

Ward IL, Weisz J (1984) Differential effects of maternal stress on circulating levels of corticosterone, progesterone and testosterone in male and female rat fetus and their mothers. Endocrinology 84:1145-1635.

Weinstock M, Fride E, Hertzberg R (1988) Prenatal stress effects on functional development of the offspring. Prog Brain Res 73:319-331. 